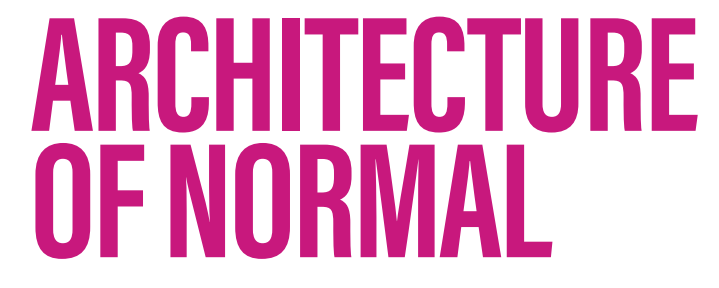




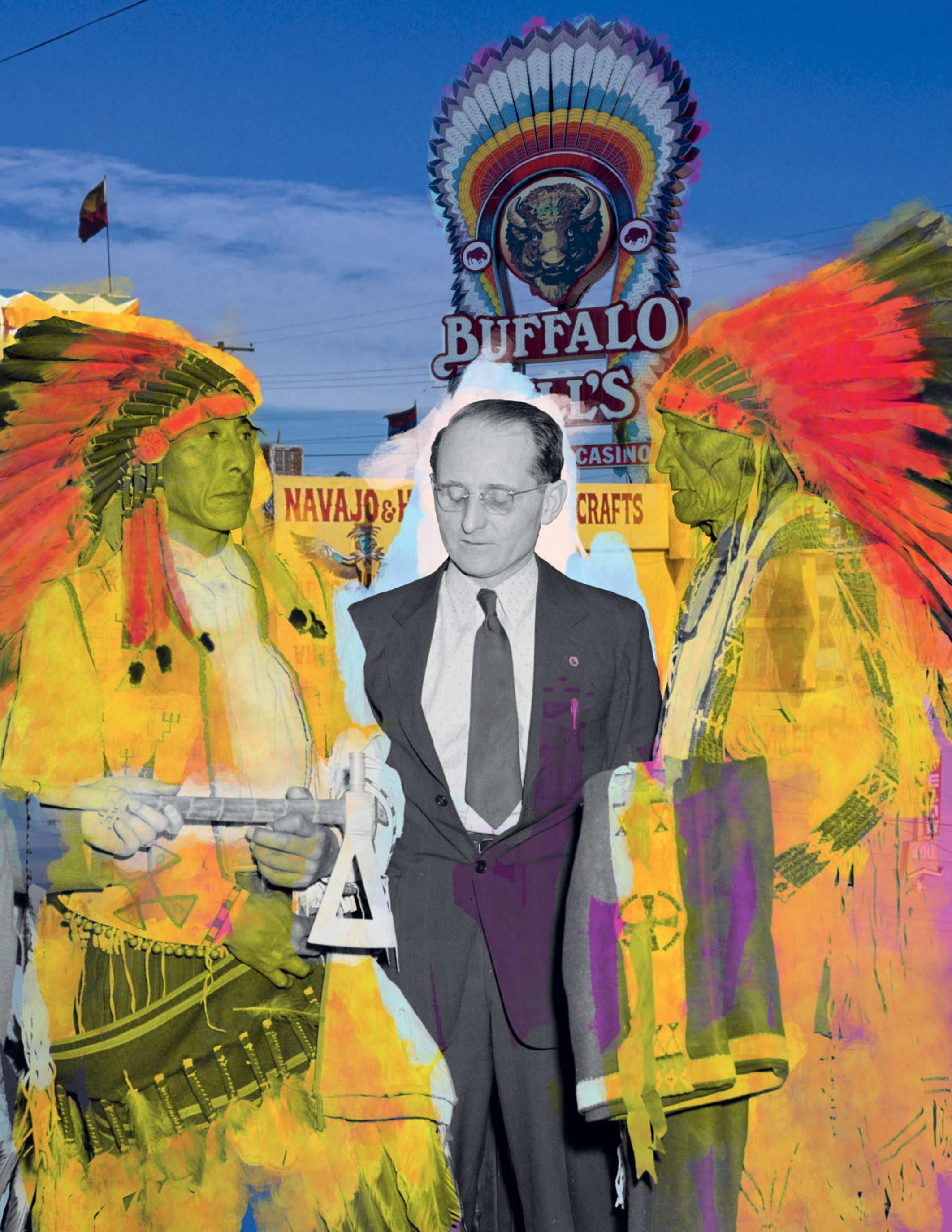




\section{DANIEL KAVEN}

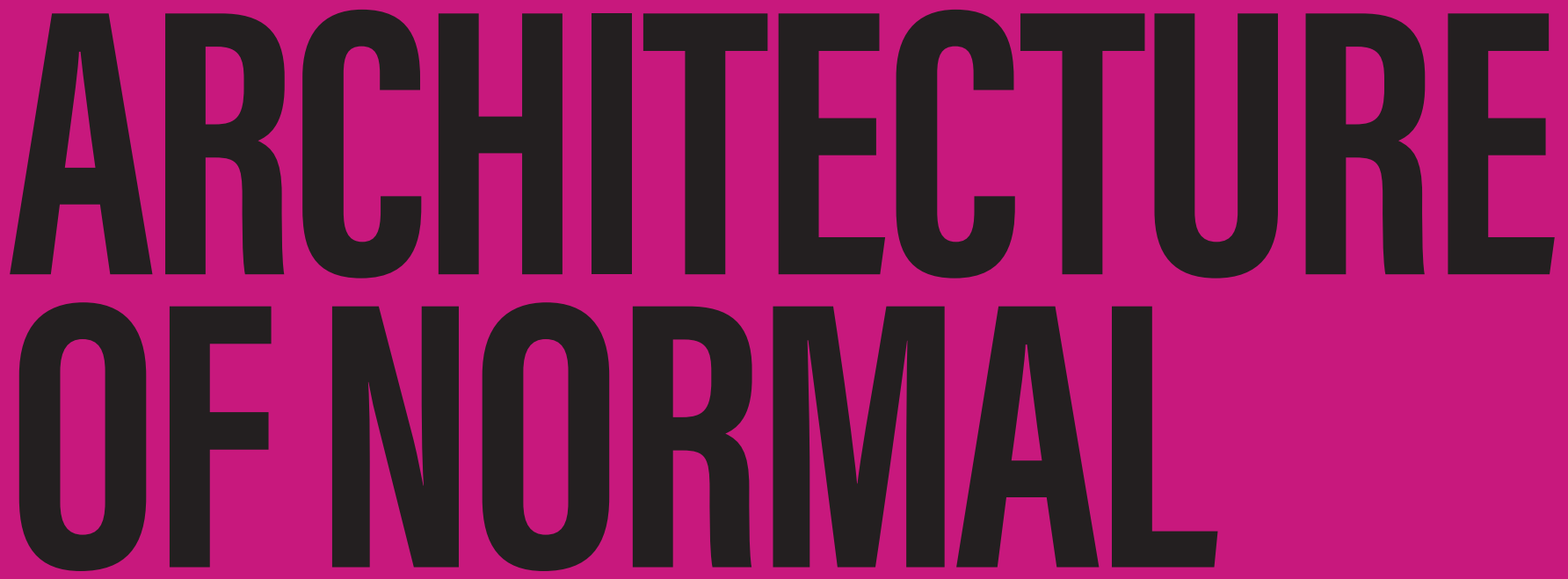

THE COLONIZATION OF THE AMERICAN LANDSCAPE

Birkhäuser Basel 


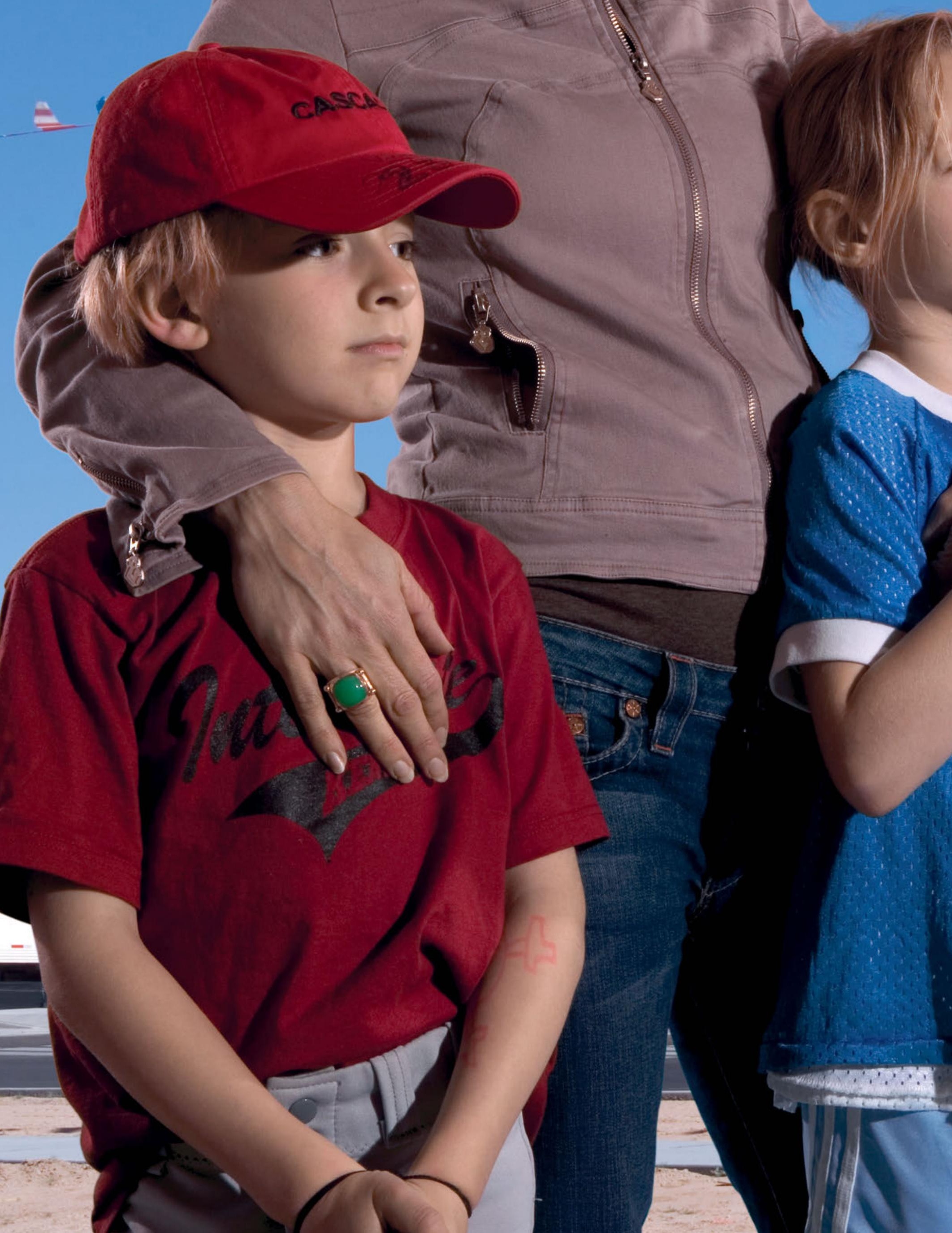




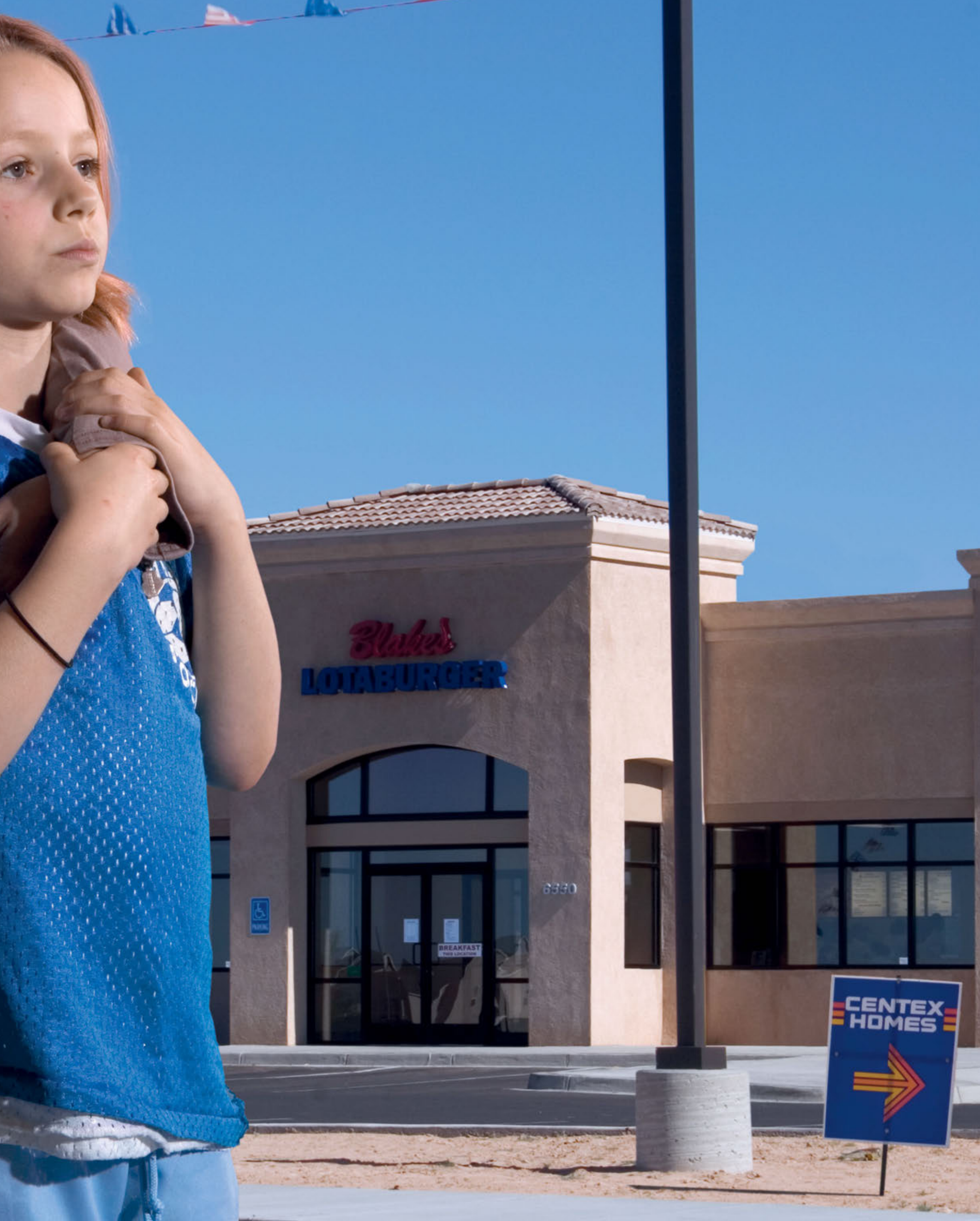


Graphic design - Daniel Kaven

Edited by - Natalie Garyet

Copy editing - Elizabeth Gregory

Project management for Birkhäuser - Ria Stein

Production - Amelie Solbrig

Paper - Profibulk, $135 \mathrm{~g} / \mathrm{m}^{2}$

Printing - Eberl \& Kœsel GmbH \& Co. KG, Altusried-Krugzell

Prepress - pixelstorm, Vienna

Library of Congress Control Number: 2021947848

Bibliographic information published by the German National Library. The German National Library lists this publication in the Deutsche Nationalbibliografie; detailed bibliographic data are available on the Internet at http://dnb.dnb.de.

This work is subject to copyright. All rights are reserved, whether the whole or part of the material is concerned, specifically the rights of translation, reprinting, re-use of illustrations, recitation, broadcasting, reproduction on microfilms or in other ways, and storage in databases. For any kind of use, permission of the copyright owner must be obtained.

ISBN 978-3-0356-2438-0

e-ISBN (PDF) 978-3-0356-2440-3

(C) 2022 Birkhäuser Verlag $\mathrm{GmbH}$, Basel

P.O. Box 44, 4009 Basel, Switzerland

Part of Walter de Gruyter $\mathrm{GmbH}$, Berlin/Boston

987654321

Printed on acid-free paper produced from chlorine-free pulp. TCF $\infty$ Printed in Germany

www.birkhauser.com 